\title{
Uptake Of Seasonal Rainfall Forecasts In Zimbabwe.
}

\author{
Terence Darlington Mushore \\ Department of Geography, Bindura University of Science Education, Zimbabwe
}

\begin{abstract}
Agriculture is mainly rain-fed in Zimbabwe and the provision of accurate rainfall information by the Meteorological Services Department is crucial to agricultural productivity in the country. The seasonal rainfall forecasts are used as an early warning tool produced with a lead time of at least 3 months such that it is important for the users to know their accuracy. Rainfall data and seasonal forecasts from the Meteorological Services Department were used to create 3 by 3 contingency tables for each homogeneous rainfall region which were then used to compute statistics which indicate the accuracy of the forecasts in the country. The study observed that national seasonal climate forecasts are finer and more accurate than regional (SARCOF) ones. In Zimbabwe, the forecasts were found to be 55 and 60\% accurate for the rainfall region 3, 64 and 90\% for region 2 and 73 and 80\% for region 1 for the JFM and OND seasons, respectively. In all the regions the accuracy was found to be higher during the OND season than the JFM season. Limited uptake by farmers (Manatsa et al., 2012) was therefore, attributed to limited access and knowledge of the science (Patt, 2001) than to the accuracy of the forecasts. The study encourages the climate experts to reach out to the farmers to train them as well as to train all partners involved in distributing the forecasts to the users such as the Agricultural extension officers. The study also developed a new forecast interpretation tool which is handy for any user of climate data. Further research leading to forecasting of extremes such as dry spells ahead of a season and inclusion of other indicators such as the Indian Ocean Dipole could improve the accuracy of seasonal forecasts. The binary system which indicates whether there will be drought or not should be adopted into the national climate forecasting system replacing the current one which uses probabilities and three categories of possible outcomes. Keywords: seasonal forecast, rainfall region, rainfall, climate experts, Indian Ocean Dipole, Meteorological, early warning, ENSO, climate, seasons, forecast, dry spell
\end{abstract}

\section{Rainfall season in Zimbabwe}

The dry season in Zimbabwe spans from May to September while the rest of the period is generally wet and hot and thunderstorms account for a significant proportion of Zimbabwe's rainfall. The period from December to February is the wettest (Meterological Services Zimbabwe., 1981) due to the influence of the InterTropical Convergence Zone (ITCZ) mainly in January (Figure 1). There is a general eastward and northward increase in seasonal/annual precipitation such that areas to the south of the country are relatively dry (Unganai, 1996). The country is divided into 3 homogeneous rainfall regions which were devised using the principle component analysis (Manatsa, 2012). The rainfall season is split into two; October to December (OND) season and the January to March (JFM) season. The principal component analysis was done separately for each of the seasons thus homogeneous regions for OND differ with those for JFM (Meteorological Services Zimbabwe., 2011). Summer rainfall in Zimbabwe is predictable and early provision of forecasts is important since the economy and large proportion of the population significantly depend on agriculture (Makarau and Jury, 1997).

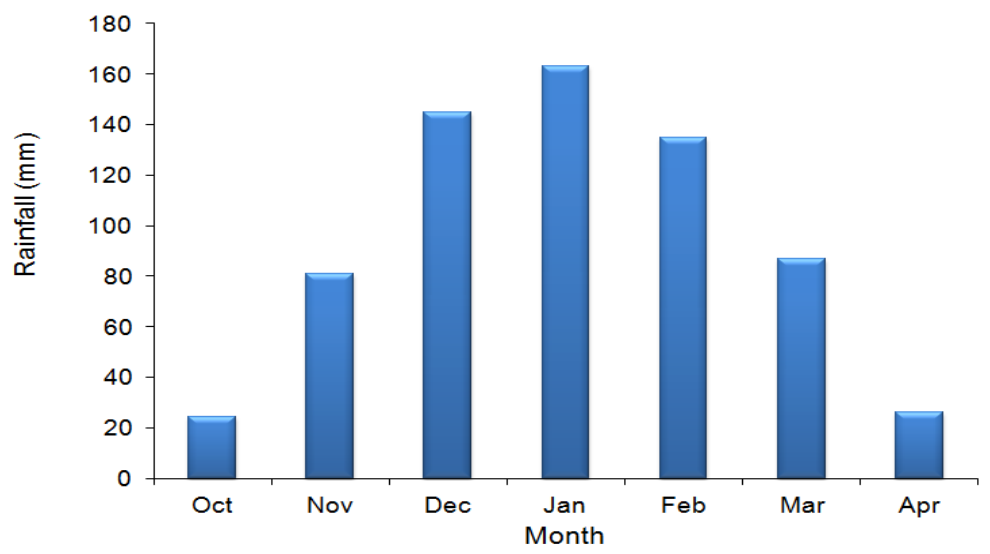

Figure 1: Distribution of rainfall in a season in Zimbabwe

Given the importance of rainfall and rainfall forecasts mentioned above, experts from National Meteorological Services of SADC countries meet annually (mostly in August) to produce forecast for the 
summer rainfall for the region (World Meteorological Organization., 2012). The Southern African Regional Climate Outlook Forum (SARCOF) is followed by national outlook forums when Meteorological experts downscale the regional forecast to their local situations. The national forecasts are then used as early warning tool especially in agriculture and related businesses. Although the climate outlook forums are still trusted by national meteorological services, recent study has claimed that the seasonal forecasts produced in the SARCOF process have very low accuracy, are unreliable and their uptake by farmers is very low (Manatsa et al., 2012). It is therefore of crucial importance that the accuracy of these forecasts be known for the benefit of the users and further researches to improve the accuracy. This will also help to verify the claim and come up with recommendations to the SADC Climate Services Centre (Coordinators and sponsors of SARCOF) which will help to improve the forecasts.

\section{Seasonal Rainfall Forecasts in Zimbabwe}

The country is divided into 3 homogeneous rainfall regions and the regions differ for OND and JFM. Manatsa et al., (2012) proposed a binary system which gives forecast as either drought or no drought but the Meteorological Services Department gives in terms of 3 categories; below normal (B), normal (N) and above normal (A). The state of the crops in a given season is not only affected by rainfall amount but also by its distribution. The forecasts could be predicting amounts with success but quality of the seasons being affected by extremes such as dry spells. This has become common in Zimbabwe when long dry spells affect quality of the JFM season as was observed in the 2011-12 season. The categories are expressed as percentages with the category with the highest percentage being the most favored and probable (Figure 2).

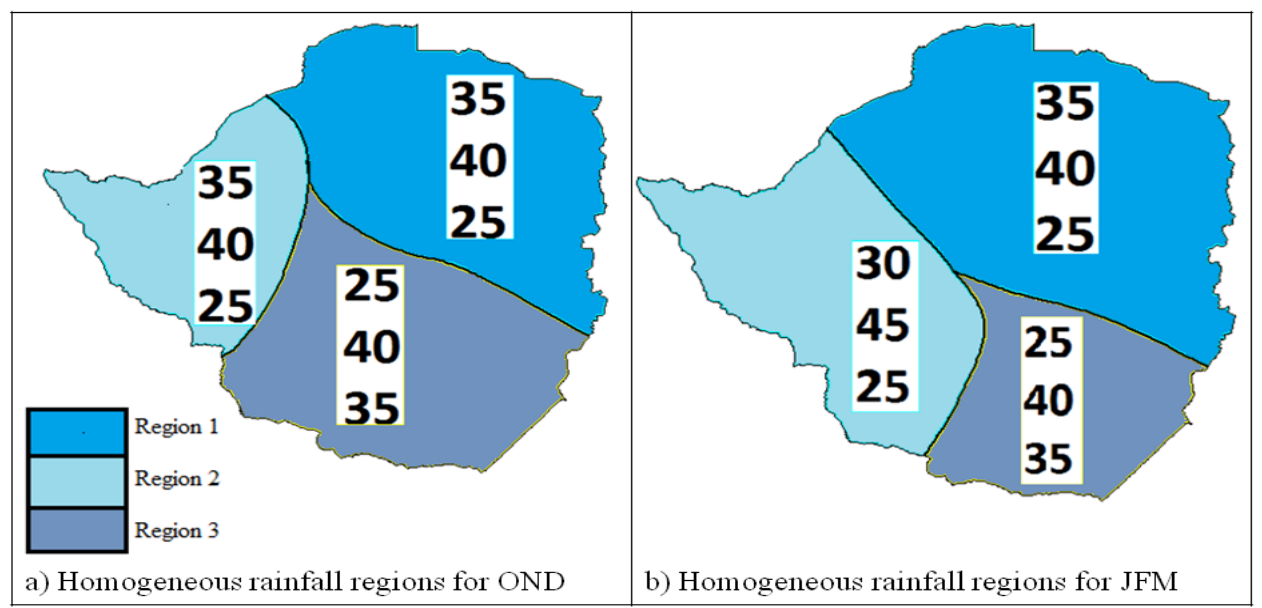

Figure 2: Homogeneous rainfall regions and normal rainfall for JFM and OND season (2011)

Figure 2 shows also that normal rainfall differs for different places/regions and also that normal rainfall for the JFM season is higher than that for the OND season. This is because the JFM season is influenced mostly by the ITCF which causes heavy and significant falls across the country (Meterological Services Zimbabwe., 1981, Unganai, 1996). Region 1 and Region 2 increase in size while Region 3 shrinks for the JFM season. The forecasts are presented to the users as in Figure 4 alerting them that although the category with the highest percentage is the one favored by the forecast, possibilities of the other categories taking place should not be ignored (Meteorological Services Zimbabwe., 2011).

\section{Categorization of the observed rainfall at the end of the season}

The observed rainfall is also expressed in terms of the categories below normal (B), normal (N) and above normal (A) at the end of each rainfall season. This is done in order to compare the amounts received with the forecast. An area is categorized as below normal when the amount received is less than $75 \%$ of the long term average for that area. Normal category is achieved when the amount received ranges between $75 \%$ and $125 \%$ of the long term average while when the amounts exceed $125 \%$ of the long term average the area is said to have received above normal rainfall. Therefore, by comparing the number of times a category was forecast with the amount of times it was observed using contingency tables and statistics recommended by WMO can assess the accuracy and usefulness of the forecasts (Manatsa et al., 2012).

\section{Verification Method using 3 by 3 contingency table}

The contingency table, such Table 1, is used to show the number of times the forecast and the observed rainfall categories intersected in a particular way (Stanski et al., 1989). 
Uptake Of Seasonal Rainfall Forecasts In Zimbabwe.

Table 1: Structure of the contingency table used to assess the accuracy of seasonal forecasts

\begin{tabular}{|c|c|c|c|c|c|}
\hline & & \multicolumn{3}{|c|}{ FORECAST } & \multirow[t]{2}{*}{ Total } \\
\hline & & Below Normal & Normal & Above Normal & \\
\hline \multirow{4}{*}{ 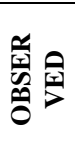 } & Below & $\mathrm{A}$ & $\mathrm{B}$ & $\mathrm{C}$ & $\mathrm{D}$ \\
\hline & Normal & $\mathrm{E}$ & $\mathrm{F}$ & $\mathrm{G}$ & $\overline{\mathrm{H}}$ \\
\hline & Above Normal & I & $\mathrm{J}$ & $\mathrm{K}$ & L \\
\hline & Total & $\mathrm{M}$ & $\mathrm{N}$ & $\mathrm{O}$ & $\mathrm{P}$ \\
\hline
\end{tabular}

Using the contingency Table 1 statistical measures of forecast accuracy can be determined as shown on Table 2 (Stanski et al., 1989).

Table 2: The statistics used to verify the forecasts and how they are computed

\begin{tabular}{|c|c|}
\hline STATISTIC & COMPUTATION \\
\hline percent correct & $100 *(\mathrm{~A}+\mathrm{F}+\mathrm{K}) / \mathrm{P}$ \\
\hline for Heidke skill score (persistence) & $0.4 *(\mathrm{M}+\mathrm{O})+0.2 * \mathrm{~N}$ \\
\hline for Heidke skill score (chance) & $(\mathrm{D} * \mathrm{M}+\mathrm{H} * \mathrm{~N}+\mathrm{L} * \mathrm{O}) / \mathrm{P}$ \\
\hline Heidke skill score (persistence) & $((\mathrm{A}+\mathrm{F}+\mathrm{K})-\mathrm{C} 1) /(\mathrm{P}-\mathrm{C} 1)$ \\
\hline Heidke skill score (chance) & $((\mathrm{A}+\mathrm{F}+\mathrm{K})-\mathrm{C} 2) /(\mathrm{P}-\mathrm{C} 2)$ \\
\hline proportion of errors of two categories - dry & $\mathrm{I} / \mathrm{M}$ \\
\hline proportion of errors of two categories - wet & $\mathrm{C} / \mathrm{O}$ \\
\hline proportion of errors of two categories - total & $(\mathrm{C}+\mathrm{I}) /(\mathrm{M}+\mathrm{O})$ \\
\hline bias - dry & $\mathrm{M} / \mathrm{D}$ \\
\hline bias-normal & $\mathrm{N} / \mathrm{H}$ \\
\hline bias - wet & $\mathrm{O} / \mathrm{L}$ \\
\hline probability of detection of a dry event & $\mathrm{A} / \mathrm{D}$ \\
\hline probability of detection of a normal event & $\mathrm{F} / \mathrm{H}$ \\
\hline probability of detection of a wet event & $\mathrm{K} / \mathrm{L}$ \\
\hline false alarm ratio of dry forecasts (FARD) & $(\mathrm{E}+\mathrm{I}) / \mathrm{M}$ \\
\hline false alarm ratio of normal forecasts (FARN) & $(\mathrm{B}+\mathrm{J}) / \mathrm{N}$ \\
\hline false alarm ratio of wet forecasts (FARW) & $(\mathrm{C}+\mathrm{G}) / \mathrm{O}$ \\
\hline reliability of dry forecasts & $\mathrm{A} / \mathrm{M}=(1-\mathrm{FARD})$ \\
\hline reliability of normal forecasts & $\mathrm{F} / \mathrm{N}=(1-\mathrm{FARN})$ \\
\hline reliability of wet forecasts & $\mathrm{K} / \mathrm{O}=(1-\mathrm{FARW})$ \\
\hline critical success index - dry (dry=below normal) & $\mathrm{A} /(\mathrm{D}+\mathrm{M}-\mathrm{A})$ \\
\hline critical success index - normal & $\mathrm{F} /(\mathrm{H}+\mathrm{N}-\mathrm{F})$ \\
\hline critical success index - wet (wet=above normal) & $\mathrm{K} /(\mathrm{L}+\mathrm{O}-\mathrm{K})$ \\
\hline
\end{tabular}

The method results in a good number of statistics the user can identify in assessing the accuracy of the forecasts. The percentage accuracy helps to directly tell if the forecasts are worthwhile or rather use other methods as tools as early warning. The bias shows the most favored forecast categories and whether this is right will then in a way be verified by the reliability and critical success index of the forecasts. The idea is not whether a category was forecast a few times but how successful the forecasts were. Another desire is to have few cases where the forecasts miss by two categories in the dry or wet direction as well as low false alarm rates.

3. Seasonal Rainfall data and national seasonal forecasts

Figure 3 shows the rainfall weather stations whose seasonal rainfall data were used and also their distribution across Zimbabwe. The length of data period used to calculate the average rainfall for the homogeneous rainfall regions was at least 30 years. Actual verification was done using the periods shown on Table 3. 


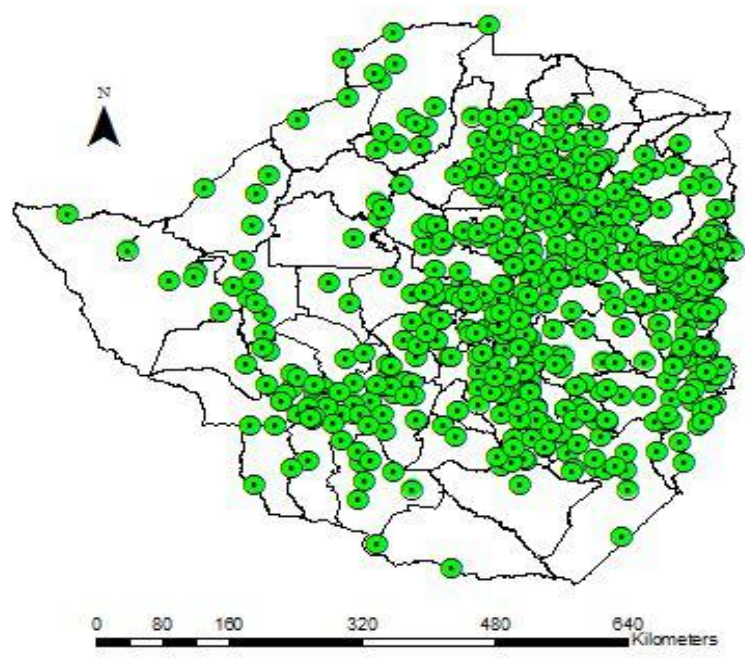

Figure 3: Distribution across Zimbabwe of the rainfall stations that were used

The National seasonal forecasts were obtained from the Meteorological Services Department. The observed state of the rainfall season was also determined as explained in section 3 above using observed rainfall data from the Meteorological Services Department as well. The forecasts and the years considered in this study were 10 for the OND seasons and 11 for the JFM seasons (Table 3).

Table 3: The forecast and observed seasonal rainfall categories used in the contingency tables

\begin{tabular}{|c|c|c|c|c|c|c|c|c|c|c|c|c|}
\hline \multirow[t]{3}{*}{ Season } & \multicolumn{6}{|c|}{ Forecast $(\mathrm{F})$ and Observed $(\mathrm{O})$ OND Season } & \multicolumn{6}{|c|}{ Forecast $(\mathrm{F})$ and observed (O) JFM Season } \\
\hline & \multicolumn{2}{|c|}{ Region 1} & \multicolumn{2}{|c|}{ Region 2} & \multicolumn{2}{|c|}{ Region 3} & \multicolumn{2}{|c|}{ Region 1} & \multicolumn{2}{|c|}{ Region 2} & \multicolumn{2}{|c|}{ Region 3} \\
\hline & F & $\mathrm{O}$ & $\mathrm{F}$ & $\mathrm{O}$ & $\mathrm{F}$ & $\mathrm{O}$ & $\mathrm{F}$ & $\mathrm{O}$ & $\mathrm{F}$ & $\mathrm{O}$ & $\mathrm{F}$ & $\mathrm{O}$ \\
\hline 1997- 1998 & $\mathrm{~N}$ & B & $\mathrm{N}$ & $\mathrm{B}$ & $\mathrm{N}$ & $\mathrm{B}$ & $\mathrm{N}$ & $\mathrm{N}$ & $\mathrm{N}$ & A & $\mathrm{N}$ & $\mathrm{N}$ \\
\hline 1998- 1999 & $\mathrm{~N}$ & A & $\mathrm{N}$ & $\mathrm{N}$ & $\mathrm{N}$ & A & $\mathrm{N}$ & A & $\mathrm{N}$ & $\mathrm{N}$ & $\mathrm{N}$ & A \\
\hline $1999-2000$ & - & - & - & - & - & - & $\mathrm{N}$ & A & $\mathrm{N}$ & A & $\mathrm{N}$ & A \\
\hline $2000-2001$ & $\mathrm{~N}$ & $\mathrm{~N}$ & $\mathrm{~N}$ & $\mathrm{~N}$ & $\mathrm{~N}$ & $\mathrm{~N}$ & A & A & A & A & A & A \\
\hline 2001-2002 & $\mathrm{N}$ & $\mathrm{N}$ & $\mathrm{N}$ & $\mathrm{N}$ & $\mathrm{N}$ & A & $\mathrm{N}$ & B & $\mathrm{N}$ & $\mathrm{B}$ & $\mathrm{N}$ & $\mathrm{B}$ \\
\hline $2007-2008$ & $\mathrm{~N}$ & $\mathrm{~N}$ & $\mathrm{~A}$ & $\mathrm{~A}$ & $\mathrm{~N}$ & $\mathrm{~N}$ & A & A & A & A & $\mathrm{N}$ & $\mathrm{N}$ \\
\hline $2008-2009$ & $\mathrm{~N}$ & $\mathrm{~N}$ & $\mathrm{~N}$ & $\mathrm{~N}$ & $\mathrm{~N}$ & $\mathrm{~N}$ & $\mathrm{~N}$ & $\mathrm{~N}$ & B & B & B & B \\
\hline $2009-2010$ & $\mathrm{~N}$ & $\mathrm{~N}$ & A & A & $\mathrm{N}$ & $\mathrm{N}$ & $\mathrm{N}$ & $\mathrm{N}$ & $\mathrm{N}$ & $\mathrm{N}$ & $\mathrm{N}$ & $\mathrm{N}$ \\
\hline $2010-2011$ & $\mathrm{~N}$ & $\mathrm{~N}$ & $\mathrm{~N}$ & $\mathrm{~N}$ & $\mathrm{~N}$ & $\mathrm{~N}$ & $\mathrm{~N}$ & $\mathrm{~N}$ & $\mathrm{~N}$ & $\mathrm{~N}$ & B & $\mathrm{N}$ \\
\hline $2011-2012$ & $\mathrm{~N}$ & $\mathrm{~N}$ & $\mathrm{~N}$ & $\mathrm{~N}$ & $\mathrm{~N}$ & $\mathrm{~N}$ & $\mathrm{~N}$ & $\mathrm{~N}$ & $\mathrm{~N}$ & $\mathrm{~N}$ & $\mathrm{~N}$ & $\mathrm{~N}$ \\
\hline
\end{tabular}

Based on Table 3 it can be seen already that the normal category was not only the most forecast over the study period but also the most observed for the years considered.

4. Accuracy of the ENSO based seasonal forecasts in Zimbabwe.

Verification was done using 3 by 3 contingency tables, data on Table 3 and the computations described on Table 2 above for each homogeneous region and the results are shown on Table 4. Some of the categories where neither forecast nor observed resulting in division by zero in some of the computations labeled as none.

Table 4: Accuracy of the seasonal forecasts for the OND season in Zimbabwe

\begin{tabular}{|c|c|c|c|}
\hline STATISTIC & Region 1 & Region 2 & Region 3 \\
\hline percent correct & 80.00 & 90.00 & 60.00 \\
\hline Heidke skill score (persistence) & 0.75 & 0.87 & 0.49 \\
\hline Heidke skill score (chance) & 0.00 & 0.75 & -0.11 \\
\hline proportion of errors of two categories - dry & None & None & 0.00 \\
\hline proportion of errors of two categories - wet & None & 0.00 & None \\
\hline proportion of errors of two categories - total & None & 0.00 & 0.00 \\
\hline bias - dry & 0.00 & 0.00 & 1.00 \\
\hline bias-normal & 1.25 & 1.14 & 1.29 \\
\hline bias-wet & 0.00 & 1.00 & 0.00 \\
\hline probability of detection of a dry event & 0.00 & 0.00 & 0.00 \\
\hline probability of detection of a normal event & 1.00 & 1.00 & 0.86 \\
\hline
\end{tabular}


Uptake Of Seasonal Rainfall Forecasts In Zimbabwe.

\begin{tabular}{|c|c|c|c|}
\hline probability of detection of a wet event & 0.00 & 1.00 & 0.00 \\
\hline false alarm ratio of dry forecasts (FARD) & None & None & 1.00 \\
\hline false alarm ratio of normal forecasts (FARN) & 0.20 & 0.13 & 0.33 \\
\hline false alarm ratio of wet forecasts (FARW) & None & 0.00 & None \\
\hline reliability of dry forecasts & None & None & 0.00 \\
\hline reliability of normal forecasts & 0.80 & 0.88 & 0.67 \\
\hline reliability of wet forecasts & None & 1.00 & None \\
\hline critical success index - dry (dry=below normal) & 0.00 & 0.00 & 0.00 \\
\hline critical success index - normal & 0.80 & 0.88 & 0.60 \\
\hline critical success index - wet (wet=above normal) & 0.00 & 1.00 & 0.00 \\
\hline
\end{tabular}

The seasonal forecasts were found to be at least $60 \%$ correct for the OND season with larger percentages correct for region $1(80 \%)$ and region $2(90 \%)$, respectively, than for homogeneous rainfall region 3 (Table 4). The percentages correct for all the regions were higher than both the Heidke skill score (chance) and Heidke skill score (persistence) implying that the procedure followed to come up with forecasts used during SARCOF is worthwhile. Although the forecast normal category was the most forecast, it was also the most observed as indicated by low false alarm rates, high critical success indices and high reliability of the normal rainfall forecasts. All statistics indicated that forecasts were more accurate for Regions 1 and 2 than for Region 3.

The forecasts for the JFM season were more than 50\% correct with lower accuracy for Region 3 than the other regions (Table 5). The percentage correct was also higher than the Heidke skill scores for persistence and chance. The normal category was the most forecast but their reliability and critical success indices were above 0.5 for all the regions implying agreement with observed rains in most of the cases (Table 5).

Table 5: Accuracy of seasonal forecasts for the JFM season in Zimbabwe

\begin{tabular}{|c|c|c|c|}
\hline STATISTIC & Region 1 & Region 2 & Region 3 \\
\hline percent correct & 72.73 & 63.64 & 54.55 \\
\hline Heidke skill score (persistence) & 0.64 & 0.50 & 0.38 \\
\hline Heidke skill score (chance) & 0.44 & 0.39 & 0.26 \\
\hline proportion of errors of two categories - dry & None & 0.00 & 0.00 \\
\hline proportion of errors of two categories - wet & 0.00 & 0.00 & 0.50 \\
\hline proportion of errors of two categories - total & 0.00 & 0.00 & 0.25 \\
\hline bias - dry & 0.00 & 0.50 & 0.67 \\
\hline bias-normal & 1.50 & 1.40 & 1.40 \\
\hline bias - wet & 0.50 & 0.75 & 0.67 \\
\hline probability of detection of a dry event & 0.00 & 0.50 & 0.33 \\
\hline probability of detection of a normal event & 1.00 & 0.80 & 0.80 \\
\hline probability of detection of a wet event & 0.50 & 0.50 & 0.33 \\
\hline false alarm ratio of dry forecasts (FARD) & None & 0.00 & 0.50 \\
\hline false alarm ratio of normal forecasts (FARN) & 0.33 & 0.43 & 0.43 \\
\hline false alarm ratio of wet forecasts (FARW) & 0.00 & 0.33 & 0.50 \\
\hline reliability of dry forecasts & None & 1.00 & 0.50 \\
\hline reliability of normal forecasts & 0.67 & 0.57 & 0.57 \\
\hline reliability of wet forecasts & 1.00 & 0.67 & 0.50 \\
\hline critical success index - dry (dry=below normal) & 0.00 & 0.50 & 0.25 \\
\hline critical success index - normal & 0.67 & 0.50 & 0.50 \\
\hline critical success index - wet (wet=above normal) & 0.50 & 0.40 & 0.25 \\
\hline
\end{tabular}

However, although lower accuracy of the forecasts for both seasons was found in Region 3 than the other regions in this study, it was not as higher than that as observed for Chiredzi when SARCOF forecasts (Manatsa et al., 2012) instead of down-scaled forecasts are used. The seasonal forecasts SADC Climate Services Centre website are consensus forecasts not down-scaled to the Zimbabwean situation while the forecasts used in this study were obtained from the Meteorological Services Department of Zimbabwe and down-scaled to the

Zimbabwean scenarios. Regional forecasts are courser in resolution than national forecasts as they divide the region into large homogeneous rainfall regions which ignore much localized causes of rainfall variability.

Therefore, seasonal forecasts down-scaled to national scales are more reliable than regional forecasts. In order to enhance their usefulness, the national seasonal forecasts should be expressed in languages understood by users such as small holder farmers. Expressing the forecasts using a binary system of drought or no drought recommended by Manatsa, et al., (2012) will also help increase the uptake and usefulness of these forecasts. This study, therefore, is of the notion that small holder farmers have limited understanding of the 
forecasts and also have limited access to them while the forecasts are statistically fairly accurate. Patt (2001) and Manatsa et al., (2012) cited that farmers lack understanding of scientific information. In most of the cases they receive the information through partners of the Meteorological Services Department and not directly which is subject to difficulties in interpretation and distortion. The Meteorological Services Department can mostly reach up to Province level where they mostly meet with technical experts and not the communal farmers. The other dissemination avenues such as internet, print media and electronic media are hardly accessed by most communal farmers or at least their effectiveness has not yet been assessed.

\section{Proposed technique of interpreting seasonal forecasts}

The major challenge faced by stakeholders is to interpret climate forecasts while interpretation is user specific. The basic idea behind the proposed interpretation technique is that of comparing the water needs of any user with the amount of water supplied in the form of rainfall to predict whether there will be excess or deficit. This helps in planning based on the best and worst case scenarios of a given forecast.

\subsection{Implementation of the technique}

There exists a bucket in each water dependent sector/activity whose size is determined by the amount of water needed by the sector. Implications of the forecast depend on the size of the bucket and are measured by the discrepancy between the amount of water needed to completely fill the sector's bucket and that to be provided by the forecast rainfall amount. As an example, the bucket for Zimbabwe National Water Authority (ZINWA) is full when all the surface and ground water bodies are completely filled. Rainfall needs at the start of the season equate to maximum water requirements of a sector/activity minus available water at the start of the season

Rainf all needed $=$ maximum requirement by sector - available at start of season .....(1) Suppose the amount available at the start of the season is $H 1$ indicated by the first bucket below and the amount of water needed by the sector to operate optimally is $H 2, H 3$ becomes the forecast effective rainfall for the sector.
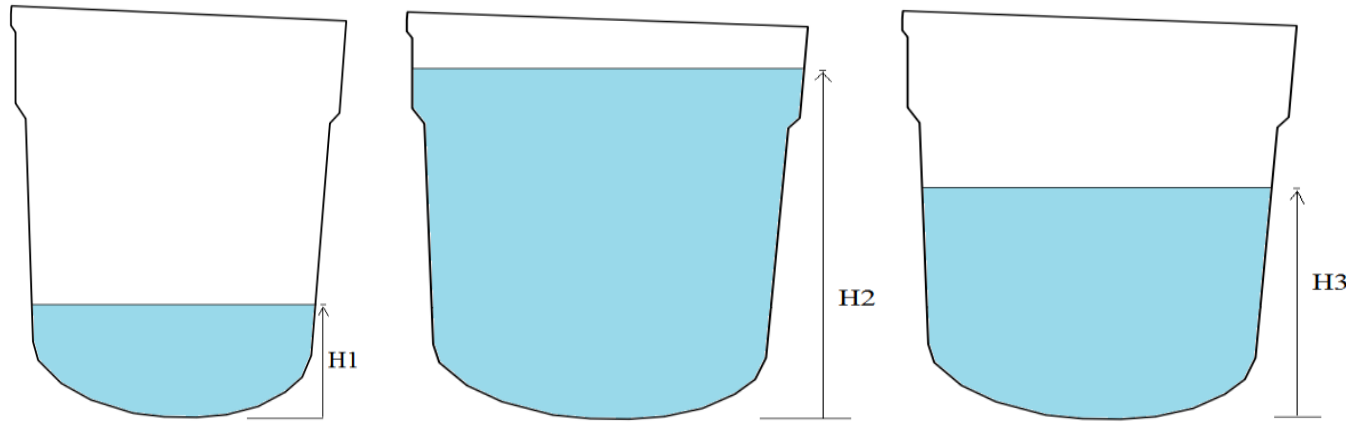

Figure 4: Buckets used to explain sector specific implications of seasonal forecasts

The effective rainfall is calculated by first converting forecast categories (B, N, A) to cumulative rainfall amounts for a season or sub-season (see Section 3). Normal rainfall for a particular place is its long term average and the 'normals' can be obtained from the Meteorological Services Department. After converting forecast categories to amounts, the next stage is to subtract all predictable losses from this and remain with an amount which directly goes to a sector or activity $H 3$. Since $H 3$ is a forecast amount it must be added to the available amount as explained by equation 1 above. The final stage of implementation will be to compare this sum with the amount $H 2$ needed by the sector or activity.

If $(H 3+H 1)<H 2$ then water deficit should be expected by the sector whose extent depends also on the magnitude of the disparity while if $(H 3+H 1)>H 2$ then the sector should expect excess water and if $(H 3+H 1)=H 2$ then the seasonal amounts expected will support the activities of a sector optimally. The techniques looks at cumulative rainfall amounts only and does not consider distribution and other properties of rainfall such as extreme events (heavy falls) that can only be predicted by short and medium range forecasts.

\section{Conclusion and recommendations}

ENSO based forecasts are accurate and reliable in predicting seasonal rainfall for Zimbabwe and farmers should make maximum use of them. However, efforts should continue to further improve their accuracy especially in Region 3 where the accuracy is 55\% for the JFM season and $60 \%$ for the OND season. The seasonal forecasts were also found to be more accurate for the OND than for the JFM season and this could be due to the impact of prolonged dry spells which mostly occur in the JFM season. It is locally more viable to use downscaled national forecasts than regional seasonal forecasts for decision making as their accuracy is higher 
than that of regional forecasts. Current problems with the uptake of the climate forecasts could be solved by educating the farmers/users and reaching out to them to bridge the existing knowledge gap. Stakeholders involved in the dissemination of the forecasts need to be trained to train the users. Since Manatsa, et al., (2012) have shown that accuracy improves when the Indian Ocean Dipole is used as an indicator of seasonal rainfall, it is also important to include this in the SARCOF forecasts and assess the impacts on accuracy at national and regional scales. A new forecast interpretation technique has been developed which is handy for any user of climate forecasts. The binary system of drought or no drought is also recommended in this study to give meaning to the forecasts from the farmers' perspectives.

\section{Acknowledgement}

This work would have never been successful without the support from the Meteorological Services Department of Zimbabwe who provided all the necessary data that were used. A special mention goes to Mr. J. Mugumbate who computed the seasonal rainfall for the years considered and searched for the seasonal forecasts in the departmental library. Dr. A. Makarau, Director of the Meteorological Services Department of Zimbabwe, serves as a source of inspiration and a role model in research. He has created an enabling environment for this work and others that came before this as well as others that are yet to come. The Almighty God inspired the whole process and provided all the strength that was used and for that we thank Him.

\section{References}

[1]. MAKARAU, A. \& JURY, M. R. 1997. Predictability of Zimbabwe summer rainfall. International Journal of Climatology, 17, 1421 1432 .

[2]. MANATSA, D., \& MUKWADA, G. 2012. Rainfall Mechanisms for the Dominant Rainfall Mode over Zimbabwe Relative to ENSO and/or IODZM. The Scientific World Journal, Volume 2012 (2012), 15.

[3]. MANATSA, D., UNGANAI, L., GADZIRAI, C. \& BEHERA, S. 2012. An innovative tailored seasonal rainfall forecasting production in Zimbabwe. Natural Hazards, 1-21.

[4]. METEOROLOGICAL SER VICES ZIMBABWE. 2011. Forecast for the 2011/12 Rainfall Season.

[5]. METEROLOGICAL SERVICES ZIMBABWE. 1981. Climate Handbook of Zimbabwe.

[6]. PATT, A. 2001. Understanding uncertainty: forecasting seasonal climate for farmers in Zimbabwe. Risk decis Policy, 6(2), 1 -15.

[7]. STANSKI, H. R., WILSON, L. J. \& BURROWS, W. R. 1989. Survey of common verification methods in meteorology. In: WMO/TD (ed.) WWW.

[8]. UNGANAI, L. S. 1996. Historic and Future Climatic Change in Zimbabwe. Climate Research, 6, $137-145$.

[9]. WORLD METEOROLOGICAL ORGANIZATION. 2012. Regional Climate Outlook Products [Online]. Geneva. Available: http://www.wmo.int/pages/prog/wcp/wcasp/clips/outlooks/climate_forecasts [Accessed 1 August 2012 2012]. 